Www.jmscr.igmpublication.org

Impact Factor (SJIF): 6.379

Index Copernicus Value: 79.54

ISSN (e)-2347-176x ISSN (p) 2455-0450

crossrefDOI: https://dx.doi.org/10.18535/jmscr/v7i1.04

Journal Of Medical Science And Clinical Research

IGM Publication

An Official Publication of IGM Publication

\title{
Intravenous Haloperidol Induced Atrial Fibrillation: A Case Report
}

\author{
Authors \\ Dr Madhumita Preetam Rauth ${ }^{1 *}$, Dr Sanjiv S. Kale ${ }^{2}$ \\ Psychiatry Dept, Dr. D. Y. Patil Medical College, Sect, 5 Nerul, Navi Mumbai, 400706 \\ *Corresponding Author \\ Dr Madhumita Preetam Rauth \\ Postal Address: Bharati Hospital, Vandemataram Chowk, Tasgaon 416312, India \\ Phone No-7709653213, Email: rimarauth@gmail.com
}

\begin{abstract}
Antipsychotic drugs are known to cause adverse cardiovascular effects such as postural hypertension, tachycardia and arrhythmias. Haloperidol is one of the antipsychotic drugs and is having adverse cardiovascular effects. This case report highlights the cardiac risk associated with use of Haloperidol, particularly if used parenterally and in elderly.
\end{abstract}

Keywords: Haloperidol, Atrial fibrillation, Antipsychotic Drug.

\section{Introduction}

Haloperidol is a typical antipsychotic of the butyrophenone family. Long-term therapy is commonly used for psychotic disorders such as schizophrenia, senile psychosis or the manic phase of bipolar disorders. Physicians not dealing with psychiatric patients are more familiar with the short-term indications in acutely confused states including the relief of delusions, delirium and aggressive behaviour.

Although haloperidol appears to function by blocking dopaminergic neuro-transmission in the central nervous system, the precise mechanism for its therapeutic effects remains unknown. It also has the potential to cause the extra pyramidal syndrome (EPS), which includes a group of movement disorders of dystonia, akathisia, tardive dyskinesia and parkinsonism. ${ }^{(2)}$
It's common cardiac side effects include hypotension, tachycardia, hypertension, cardiac arrhythmias and rarely, sudden cardiac death.

Atrial fibrillation is an abnormal heart rhythm, characterized by irregular rapid beating, leading to decreased peripheral blood flow.

Cardiac conduction defect such as ATRIAL FIBRILLATION is an unusual side effect of Haloperidol and is thought to occur due to inhibitory action of Haloperidol on the delayed rectifying potassium channel (I Kr) ("Funny Channel") (encoded by the HERG gene) - major pore forming subunit involving cardiac repolarization ${ }^{(3)}$. 


\section{Molecular level Cellular level \\ Cellular level}

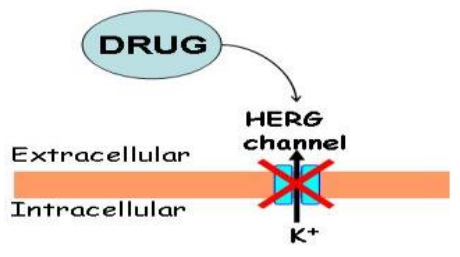

HERG blockade

bY DRUG

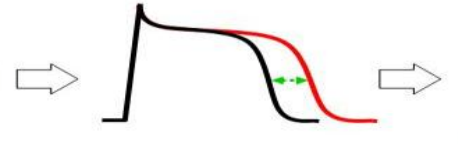

Prolongation of action potential duration by HERG channel blocker

\section{Tissue level

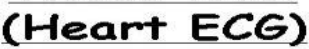

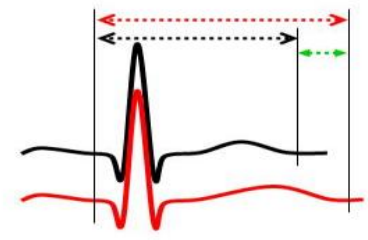

Prolongation of QT interval in ECG

\section{Cardiac Conduction defect due to Blockage of HERG Potassium Channel}

\section{Case Report}

Sixty years old male patient was brought to the emergency department of our hospital with history of insidious onset of suspiciousness, fearfulness, muttering and gesticulating to self, psychomotor retardation, pacing around, reduced self care and decreased sleep, appetite of 4 days duration.

four days after onset, patient was taken to a private physician, where routine investigations including ECG were done which were within normal limits.

Patient was injected with $5 \mathrm{mg}$ HALOPERIDOL INTRAVENOUSLY by the private physician and referred to our hospital the next day.

At the time of presentation, the patient's blood pressure was $140 / 80 \mathrm{mmHg}$, pulse was 84 per minute and regular. ECG was within normal limits.
Patient was admitted for observation in the ward and was started on Haloperidol 5mg \& Promethazine 50mg INTRAMUSCULARLY at night.

12 hours following admission patient started complaining of sweating, uneasiness and palpitations. On examination, pulse rate was 171 beats per minute $\&$ irregular and Blood Pressure was $60 \mathrm{~mm} \mathrm{Hg}$ by pulse.

\section{ECG revealed Atrial Fibrillation}

Patient was shifted to ICU and started on Metoprolol $25 \mathrm{mg} \&$ Haloperidol was stopped.

Routine investigations including 2D Echo and Serum Electrolytes were normal.

Atrial Fibrillation resolved within 6 days and patient was discharged in a stable condition on Olanzapine $5 \mathrm{mg}$ \& Metoprolol $25 \mathrm{mg}$ and is currently maintained.

\section{Atrial Fibrillation}

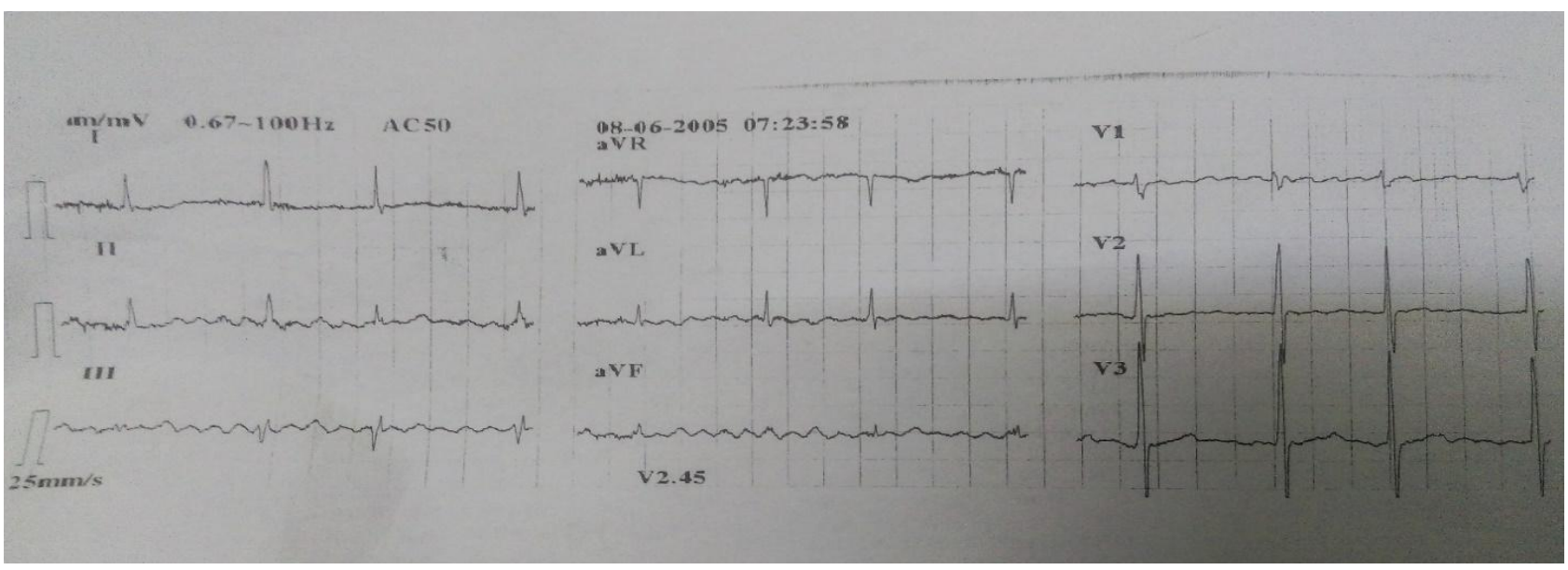




\section{Normal ECG after 6 Days}
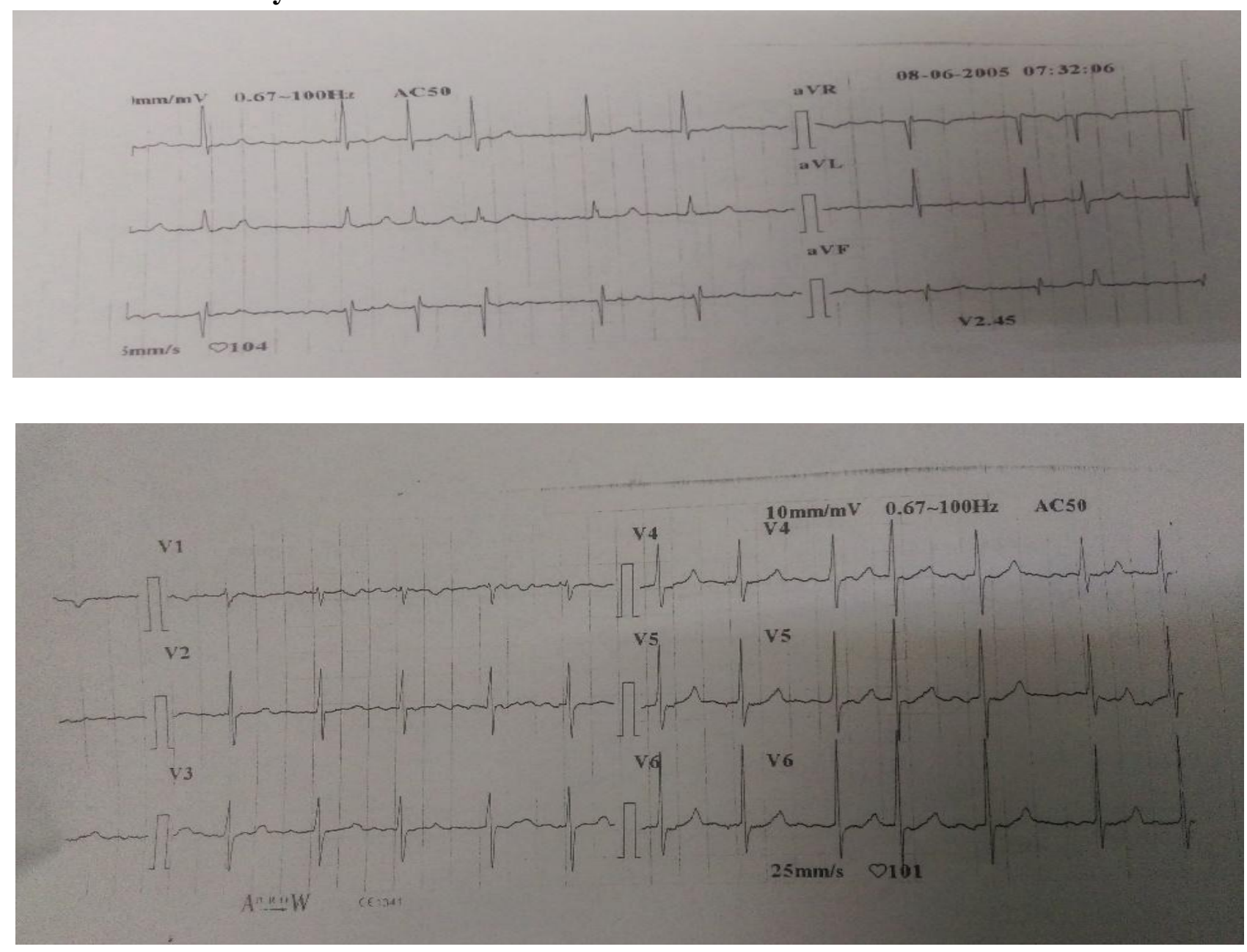

\section{Discussion}

Antipsychotic drugs are known to cause adverse cardiovascular effects such as postural hypertension, tachycardia and arrhythmias, which may occur via blocked of peripheral adrenergic and cholinergic receptors, as well as increase in sympathetic activity. ${ }^{(4)}$

As the elimination half-life of haloperidol is 17 to (5)

18 hours, it may exert prolonged effects.

There is a common perception that it controls agitation with virtually no major adverse cardiac, respiratory, renal or haematopoietic effects. However, numerous reports illustrate that serious side effects can occur in all of these systems. ${ }^{(6)}$

Case reports link antipsychotic drugs with sudden cardiac deaths, which is consistent with doserelated electrophysiologic effects ${ }^{(7)}$

It is also used in critically ill agitated and delirious patients who are unresponsive to high doses of narcotics and benzodiazepines.
This case report highlights the cardiac risk associated with use of Haloperidol, particularly if used parenterally and in elderly.

One must always be vigilant in using Antipsychotic medications in "at risk" individuals such as elderly.

\section{Acknowledgement}

I dedicate my humble thanks to my teacher and guide, Dr. Sanjiv S Kale, Professor and Head, Dept. of Psychiatry, of my Medical College, his profound knowledge has guided me and has shown me the path towards this article.

I am thankful to the Dean, of my Medical College, for his co-operation in conducting the study. I am also thankful to all the other staff of my department and also my colleagues. Lastly I am thankful to my family and almighty God. 


\section{References}

1. Sigma Pharmaceuticals Pty Ltd. Product Monograph. 2003.

2. Gerlach J, Korsgaard S. Classification of abnormal involuntary movements in psychiatric patients. Neuropsychiatr Clin 1983;2:201-208.

3. J.Y.T. Leung et al. Cardiovascular sideeffects of antipsychotic drugs: The role of the autonomic nervous system. Pharmacology \& Therapeutics 135 (2012) 113-122

4. H. Suessbrich et al. The inhibitory effect of the antipsychotic drug haloperidol on HERG potassium Jm channels expressed in Xenopus oocytes. British journal of Pharmacology 120 (1997) 968-974

5. Froemming JS, Lam YW, Jann MW, Davis CM. Pharmacokinetics of haloperidol. Clin Pharmacokinet 1989; 17:396-423.

6. Hennessy S, Bilker WB, Knauss JS, et al. Cardiac arrest and ventricular arrhythmia in patients taking antipsychotic drugs: cohort study using administrative data. BMJ 2002;325:1070.

7. Wayne A. Ray et al. Antipsychotics and the risk of Sudden Cardiac Death. Arch Gen Psychiatry Vol 58, Dec 2001. 